\title{
Controlled scrambling in porphyrin synthesis - selective synthesis of 5,10-disubstituted porphyrins
}

\author{
Andrew N. Cammidge* and Orhan Öztürk \\ School of Chemical Sciences, University of East Anglia, Norwich NR4 7TJ, UK \\ Received 30 October 2000; accepted 7 November 2000
}

Abstract-Condensation of phenyldipyrromethane with bisnaphthaldehyde 3 leads to unexpected formation of the scrambled 5,10-bridged porphyrin 5; this unprecedented selectivity suggests that an alternative scrambling mechanism to dipyrromethane acidolysis is operating. (C) 2000 Elsevier Science Ltd. All rights reserved.

The synthesis of porphyrins has been widely studied since the first synthesis of haemin by Fisher and Zeile in $1929 .{ }^{1}$ The interest, for the main part, stems from the wide occurrence of porphyrin derivatives in nature and the ability of natural and synthetic derivatives to act as models for biological processes (light harvesting, oxygen transport, catalysis, molecular recognition). ${ }^{2}$ Synthesis of porphyrin derivatives typically involves condensation of pyrroles with aldehydes or their equivalent., ${ }^{2,3}$ Such one-pot procedures are only generally applicable to symmetrical, tetrasubstituted derivatives. More elaborate approaches are required in the synthesis of unsymmetrically substituted porphyrins. A widely used approach uses preformed dipyrromethanes. Their condensation with aldehyde gives access to derivatives with reduced symmetry. ${ }^{2,4}$
In nature, elaborate porphyrin derivatives are built up via stepwise biosynthesis to give tetrapyrrolic intermediates (bilanes) which are then cyclised to the porphyrinogen (which is subsequently oxidised to porphyrin). Much work has gone into elaborating the biosynthetic pathway for their synthesis. In nature there is often quite remarkable control and this is exemplified by the biosynthesis of vitamin $B_{12}$ during which a bilane is cyclised with concomitant inversion of one of the pyrrole units. Such 'scrambling' of pyrroles in chemical synthesis is well documented but is usually an unwanted and uncontrolled side reaction. ${ }^{2,5}$ Here, we report the first example of controlled scrambling in porphyrin synthesis leading to selective synthesis of a 5,10-disubstituted porphyrin.
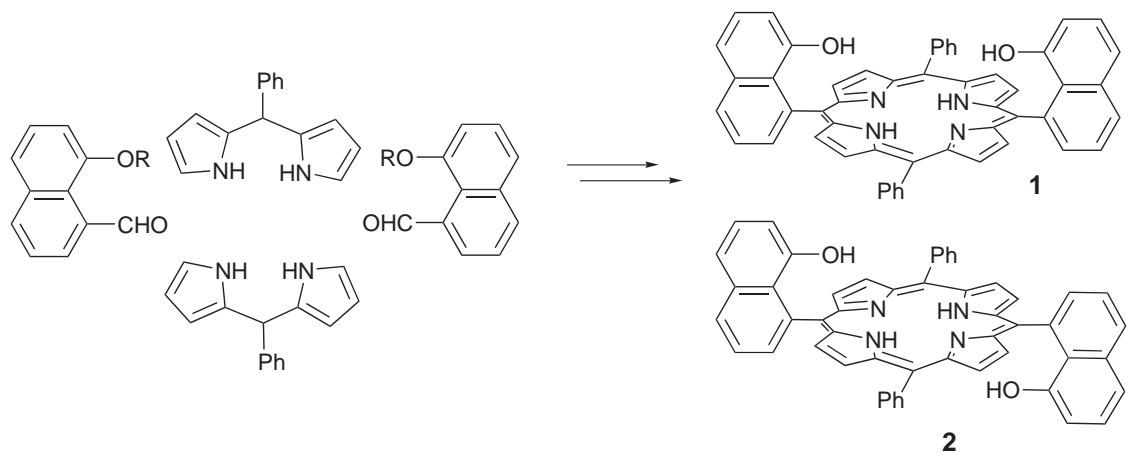

Scheme 1.

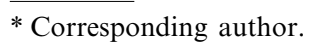

0040-4039/01/\$ - see front matter (C) 2000 Elsevier Science Ltd. All rights reserved.

PII: S0040-4039(00)01965-1 
As part of a study aimed at the synthesis of efficient molecular recognition hosts based on the metalloporphyrin platform, we targeted derivatives such as $\mathbf{1}$ which incorporate 8-hydroxyl-substituted naphth-1-yl substituents at the 5- and 15-porphyrin meso positions to produce a tight cleft directly above the porphyrin plane. ${ }^{6}$ Naphth-1-yl porphyrins are stable to isomerism (atropisomerism) because of sterically restricted rotation. ${ }^{6}$ A statistical synthesis (using a dipyrromethanes and 8-substituted naphth-1-aldehyde) would therefore be expected to yield two isomers (Scheme 1).

In order to overcome this problem we adopted a strategy which involved presynthesis of a bis-naphthaldehyde to force production of a single atropisomer. $p$-Xylyl was chosen as the linking ${ }^{7}$ group because a simple molecular model indicated that it could be accommodated across the porphyrin with minimal strain and it was envisaged that it could be easily removed to reveal the single atropisomer dihydroxide. Compound 3 was therefore synthesised (by reaction of 2 equivalents of 8-hydroxynaphth-1-aldehyde ${ }^{8}$ with $\alpha, \alpha^{\prime}$-dibromo- $p$ xylene) and condensed with phenyldipyrromethane ${ }^{9}$ using $\mathrm{BF}_{3} \cdot \mathrm{OEt}_{2}$ as catalyst under standard conditions for porphyrin synthesis. Quite remarkably, however, condensation of the dialdehyde with phenyldipyrromethane did not yield the expected 5,15-bridged porphyrin 4 but gave the 5,10 bridged isomer $5^{10}$ (Scheme 2). The structure of $\mathbf{5}$ was elucidated initially by analysis of its ${ }^{1} \mathrm{H}$ NMR spectrum, which was significantly more complex than that expected for 4. Two doublets and a broad resonance (which does not sharpen significantly at $80^{\circ} \mathrm{C}$ ) are observed for the $\alpha$-protons and phenyl protons, respectively, of the xylyl bridge. The structure was confirmed by X-ray crystallography. ${ }^{11}$ Subsequent careful examination of the reaction mixture allowed isolation of a trace $(<1 \%)$ of the expected 5,15-bridged porphyrin 4 .

Scrambling in related dipyrromethane/aldehyde syntheses is usually interpreted as arising from breakdown of the dipyrromethane under the acidic reaction conditions, eventually giving a complex mixture of all possible porphyrins. ${ }^{5 \mathrm{~d}}$ From the observation that $\mathbf{5}$ and tetraphenylporphyrin (TPP) are the main porphyrin products from this reaction it is likely that an alterna- tive mechanism is operating (Scheme 3). Normal electrophilic aromatic substitution at the 5-position of the dipyrromethane by naphthaldehyde gives intermediate 6. Electrophilic substitution at the $5^{\prime}$-position of the second pyrrole of the dipyrromethane with the second naphthaldehyde of the dimer (path A) would lead to the (expected) 5,15-bridged porphyrin. However, it would appear that attack at the 2-position of the substituted pyrrole is preferred (path B) to give intermediate 7. Fragmentation of 7 can occur to give cyclic 2,5-disubstituted pyrrole 8 and pyrrolic carbocation 9. Compound $\mathbf{8}$ can react further with another equivalent of dipyrromethane and 9 (directly or sequentially) with cyclisation to give the porphyrinogen which, on oxidation, gives the observed 5,10-bridged isomer. Production of a small quantity of TPP is easily explained by this mechanism (tetramerisation of 9).

It is plausible that this mechanism may operate quite generally in porphyrin syntheses. Noting that it implicates carbocation 9, we undertook a further study to seek conditions designed to suppress this pathway and thereby demonstrate control over the fate of species $\mathbf{6}$. We reasoned that destabilisation of the carbocation would disfavour this fragmentation and promote formation of the 'normal' 5,15-disubstituted product. This was indeed found to be the case. Repetition of the reaction using (pentafluorophenyl)-dipyrromethane leads to total elimination of the fragmentation/scrambling pathway and exclusive isolation of the 5,15bridged porphyrin $\mathbf{1 0}$ in $12 \%$ yield (Scheme 3 ).

The original target, 4, was eventually synthesised according to Scheme 4. Bisnaphthaldehyde 3 was condensed with an excess of pyrrole to yield bis(dipyrromethane) 11. Compound $\mathbf{1 1}$ was further condensed with benzaldehyde in the presence of zinc acetate using propionic acid in dichloromethane ${ }^{12}$ to give $\mathbf{4}$ as its zinc complex $(\mathbf{4 Z n}) .{ }^{10} \mathrm{It}$ is particularly noteworthy that $\mathbf{5}$ is not formed when $\mathbf{1 1}$ is treated with benzaldehyde under identical conditions to those used for its formation from 3 and phenyldipyrromethane. This important observation lends further support for the alternative mechanism because any acidolysis of the (bis)dipyrromethane would lead to rapid formation of the 5,10-bridged product.
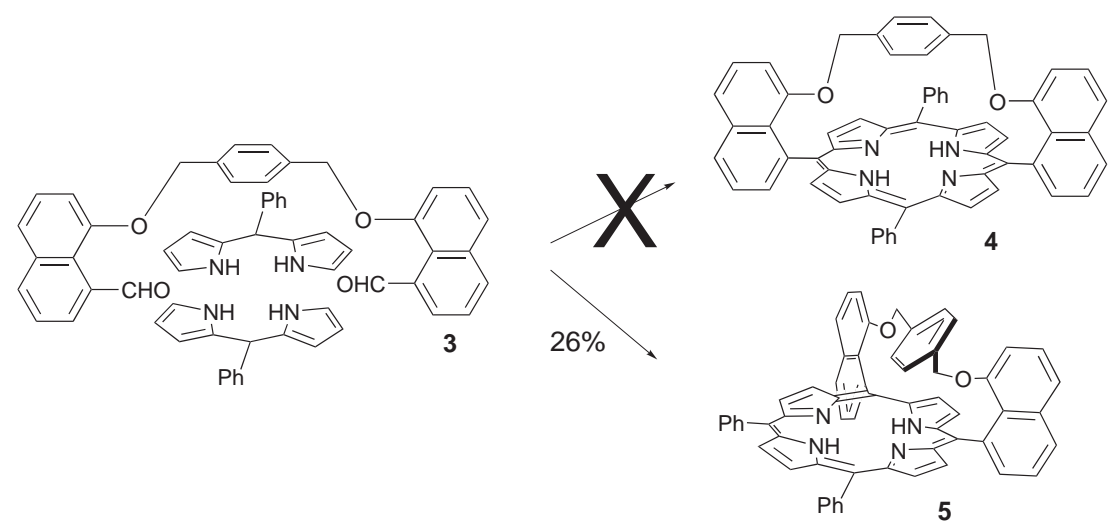

Scheme 2. 


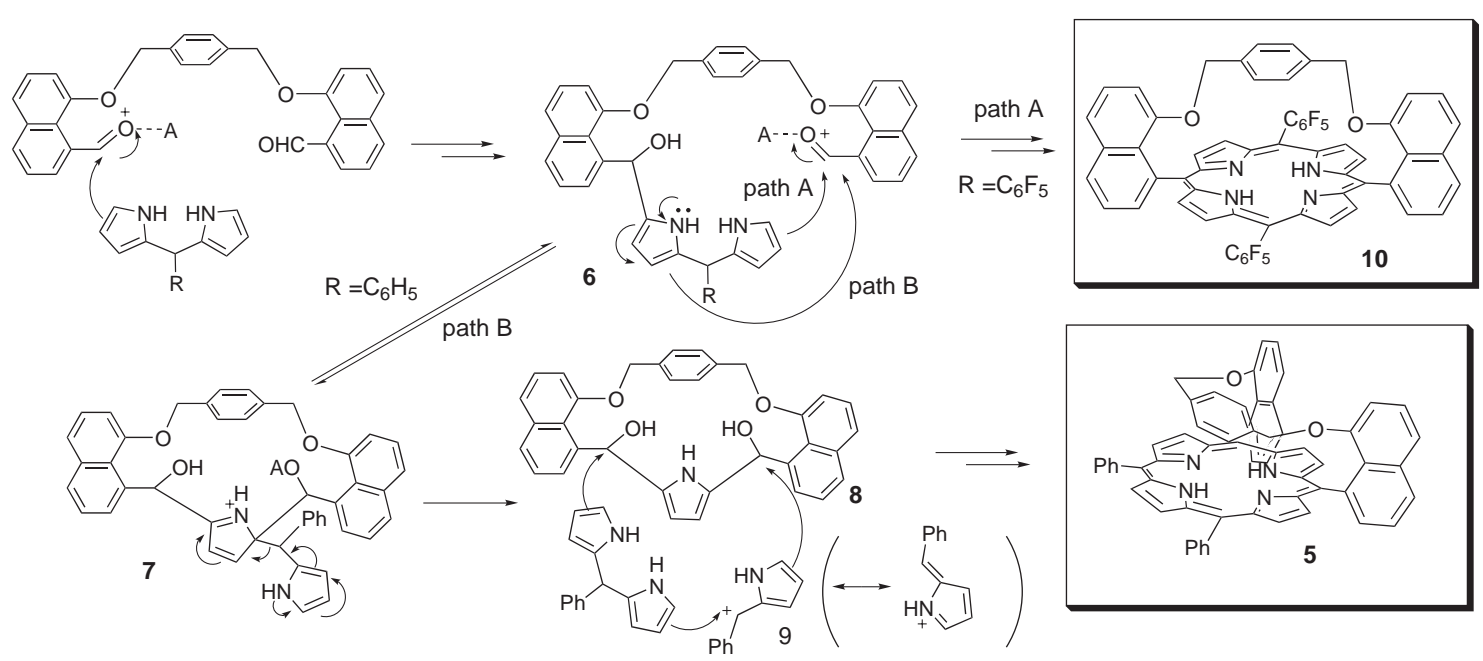

Scheme 3. Alternative mechanism for scrambling leading to $\mathbf{5}$.
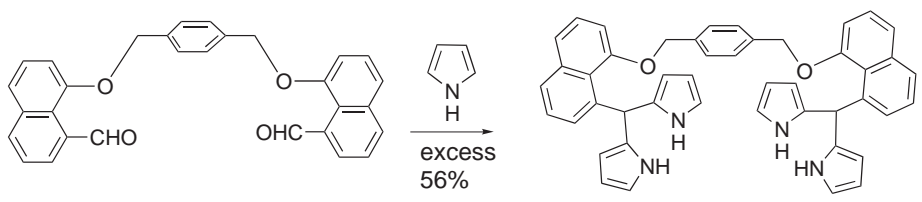

11
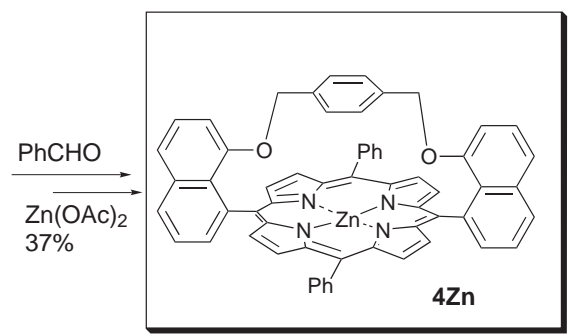

Scheme 4.

Further work is in progress to determine the generality of this process and to deprotect and elaborate the novel porphyrins for investigation as molecular recognition hosts.

\section{Acknowledgements}

We thank the EPSRC mass spectrometry service (Swansea, UK) for FAB and accurate mass measurements.

\section{References}

1. (a) Fischer, H.; Zeile, K. Liebigs Ann. Chem. 1929, 468, 98. (b) Fischer, H.; Orth, H. Die Chemie des pyrrols; Akademische Verlag: Leipzig, 1934; Vol. 1. (c) Fischer, H.; Orth, H.; Die Chemie des pyrrols; Akademische Verlag: Leipzig, 1937; Vol. 2, part 1. (d) Fischer, H.; Stern, A. Die Chemie des pyrrols; Akademische Verlag: Leipzig, 1940; Vol. 2, part 2.

2. The Porphyrin Handbook; Kadish, K. M.; Smith, K. M.; Guilard, R., Eds.; Academic Press: Boston, 2000; Vols. $1-10$.

3. (a) Adler, A. D.; Longo, R. F.; Finarelli, J. D.; Goldmacher, J.; Assour, J.; Korsakoff, L. J. Org. Chem. 1967, 32, 476. (b) Lindsey, J. S.; Schreiman, I. C.; Hsu, H. C.;
Kearney, P. C.; Marguerettaz, A. M. J. Org. Chem. 1987, $52,827$.

4. Ogoshi, H.; Sugimoto, H.; Nishiguchi, T.; Watanabe, T.; Matsuda, Y.; Yoshida, Z. I. Chem. Lett. 1978, 29.

5. (a) Shanmugathasan, S.; Edwards, C.; Boyle, R. W. Tetrahedron 2000, 56, 1025. (b) Littler, B. J.; Ciringh, Y.; Lindsey, J. S. J. Org. Chem. 1999, 64, 2864. (c) Davoust, E.; Granet, R.; Krausz, P.; Carré, V.; Guilloton, M. Tetrahedron Lett. 1999, 40, 2513. (d) Wallace, D. M.; Leung, S.; Senge, M. O.; Smith, K. M. J. Org. Chem. 1993, 58, 7245 .

6. Meso-naphth-1-yl porphyrins bearing hydroxyl substituents at the 2- and/or 7-positions have been reported. (a) Mizutani, T.; Kurahashi, T.; Murakami, T.; Matsumi, N.; Ogoshi, H. J. Am. Chem. Soc. 1997, 119, 8991. (b) Hayashi, T.; Miyahara, T.; Koide, N.; Kato, Y.; Masuda, H.; Ogoshi, H. J. Am. Chem. Soc. 1997, 119, 7281. (c) Mizutani, T.; Murakami, T.; Ogoshi, H. Tetrahedron Lett. 1996, 37, 5369. (d) Hayashi, T.; Miyahara, T.; Aoyama, Y.; Nonoguchi, M.; Ogoshi, H. Chem. Lett. 1994, 1749. (e) Hayashi, T.; Miyahara, T.; Hashizumi, N. Ogoshi, H. J. Am. Chem. Soc. 1993, 115, 2049. (f) Hayashi, T.; Asai, T.; Hokazono, H.; Ogoshi, H. J. Am. Chem. Soc. 1993, 115, 12210. (g) Hayashi, T.; Miyahara, T.; Aoyama, Y.; Ogoshi, H. Pure Appl. Chem. 1994, 66, 797.

7. Wang, Q. M.; Bruce, D. W. Tetrahedron Lett. 1996, 37, 7641. 
8. (a) Packer, R. J.; Smith, D. C. C. J. Chem. Soc. (C) 1967, 2194. (b) Elliger, C. A. Org. Prep. Proc. Int. 1985, 17, 419.

9. Lee, C. H.; Lindsey, J. S. Tetrahedron 1994, 50, 11427.

10. Selected data. Compound 5: $\mathrm{mp}>300^{\circ} \mathrm{C}, \lambda_{\max }(\mathrm{DCM}) /$ $\mathrm{nm} 425.5,520.0,557.0,597.5,653.5 ; \delta_{\mathrm{H}}(270 \mathrm{MHz}$, $\left.\mathrm{CDCl}_{3}\right)$ (at $\left.24^{\circ} \mathrm{C}\right):-2.49(2 \mathrm{H}$, br s, $-\mathrm{NH}), 3.52(2 \mathrm{H}, \mathrm{d}$, $\left.J=10.2,-\underline{\mathrm{CH}}_{2}-\mathrm{Ph}-\underline{\mathrm{CH}}_{2}-\right), 3.91-3.94\left(4 \mathrm{H}\right.$, br s, $-\mathrm{CH}_{2}-\mathrm{Ph}-$ $\left.\mathrm{CH}_{2}-\right), 4.13\left(2 \mathrm{H}, \mathrm{d}, J=10.2,-\underline{\mathrm{CH}}_{2}-\mathrm{Ph}-\underline{\mathrm{CH}}_{2}-\right), 6.79(2 \mathrm{H}, \mathrm{d}$, $J=7.6), \quad 7.53 \quad(2 \mathrm{H}, \quad \mathrm{t}, \quad J=7.6), 7.62-7.79 \quad(10 \mathrm{H}, \mathrm{m}$, napth. $+\mathrm{Ph}), 7.93(2 \mathrm{H}, \mathrm{d}, J=6.9), 8.07(2 \mathrm{H}, \mathrm{m}, \mathrm{Ph}), 8.17$ $(4 \mathrm{H}, \mathrm{m}$, pyrrole + naphth $), 8.33(2 \mathrm{H}, \mathrm{m}, \mathrm{Ph}), 8.55(2 \mathrm{H}, \mathrm{s}$, pyrrole), $8.59(2 \mathrm{H}, \mathrm{d}, J=4.6$, pyrrole $), 8.85(2 \mathrm{H}, \mathrm{s}$, pyrrole); $\delta_{\mathrm{C}}\left(67.4 \mathrm{MHz}, \mathrm{CDCl}_{3}\right): 69.63,77.22,106.27$, $119.19,120.70,123.16,124.18,126.36,126.55,127.45$, $127.96,128.28,129.56,133.76,134.41,134.62,134.96$, $137.80,142.55,156.04 ; \mathrm{m} / z$ acc mass (calcd) 848.315127 $\left(\mathrm{M}^{+}\right)$, (found) $848.3171\left(\mathrm{M}^{+}\right)$. Compound 4.Zn: $\mathrm{mp}>$ $300^{\circ} \mathrm{C}, \lambda_{\max }(\mathrm{DCM}) / \mathrm{nm}: 426.0,553.0,596.0 ; \delta_{\mathrm{H}}(270$ $\left.\mathrm{MHz}, \mathrm{CDCl}_{3}\right): 3.07\left(4 \mathrm{H}, \mathrm{s},-\mathrm{CH}_{2} \mathrm{PhCH}_{2}-\right), 3.68(4 \mathrm{H}, \mathrm{s}$, $\left.-\mathrm{CH}_{2} \mathrm{PhCH}_{2}{ }^{-}\right), 6.51(2 \mathrm{H}, \mathrm{d}, J=7.6), 7.38(2 \mathrm{H}, \mathrm{t}, J=8.1)$,
$7.68(6 \mathrm{H}, \mathrm{m}, \mathrm{Ph}), 7.79(2 \mathrm{H}, \mathrm{d}, J=8.6), 7.87(2 \mathrm{H}, \mathrm{t}$, $J=7.8), 8.15(4 \mathrm{H}, \mathrm{m}, \mathrm{Ph}), 8.25(2 \mathrm{H}, \mathrm{d}, J=8.3), 8.51(2 \mathrm{H}$, $\mathrm{d}, J=6.9), 8.62(4 \mathrm{H}, \mathrm{d}, J=4.6), 8.74(4 \mathrm{H}, \mathrm{d}, J=4.6) ; \delta_{\mathrm{C}}$ $\left(75.4 \mathrm{MHz}, \quad \mathrm{CDCl}_{3}\right): 69.34 \quad\left(-\mathrm{CH}_{2} \mathrm{PhCH}_{2}-\right), 77.19$ $\left.\mathrm{CH}_{2} \mathrm{PhCH}_{2}-\right), 109.57,120.18, \overline{122.30}, \overline{123} .07,123.32$, $124.09,126.28,126.48,127.20,128.50,128.89,130.99$, $131.44,132.95,134.28,134.93,138.38,143.16,149.21$, 149.86, 155.81; $\mathrm{m} / z(\mathrm{FAB}) 912\left(\mathrm{M}^{+}\right)$. Compound 10: $\mathrm{mp}$ $>320^{\circ} \mathrm{C}, \lambda_{\max }(\mathrm{DCM}) / \mathrm{nm}: 422.0,516.0,551.0,595.0$, $652.0 ; \delta_{\mathrm{H}}\left(270 \mathrm{MHz}, \mathrm{CDCl}_{3}\right):-3.33(2 \mathrm{H}, \mathrm{s},-\mathrm{NH}), 3.06$ $\left(4 \mathrm{H}, \mathrm{s},-\mathrm{CH}_{2} \mathrm{PhCH}_{2}-\right), 3.67\left(4 \mathrm{H}, \mathrm{s},-\mathrm{CH}_{2} \mathrm{PhCH}_{2}-\right), 6.48$ $(2 \mathrm{H}, \mathrm{d}, J=7.6), 7.37(2 \mathrm{H}, \mathrm{t}, J=7.9), 7.75(2 \mathrm{H}, \mathrm{d}, J=$ 7.9), $7.85(2 \mathrm{H}, \mathrm{t}, J=7.6), 8.23(2 \mathrm{H}, \mathrm{d}, J=7.8), 8.43(2 \mathrm{H}$, $\mathrm{d}, J=6.9), 8.50(8 \mathrm{H}, \mathrm{dd}, J=4.6,4.3) ; \delta_{\mathrm{C}}(67.4 \mathrm{MHz}$, $\left.\mathrm{CDCl}_{3}\right): 69.27,108.78,122.03,123.55,123.73,124.09$, $126.66,128.42,129.03,131.71,131.93,134.93,136.92$, $155.50 ; m / z$ (FAB) $1029\left(\mathrm{M}^{+}+1\right)$.

11. The crystal structures of $\mathbf{4 Z n}$ and 5 will be reported elsewhere.

12. Setsune, J.; Hashimoto, M.; Shiozawa, K.; Hayakawa, J.; Ochi, T.; Masuda, R. Tetrahedron 1998, 54, 1407. 